\title{
Improvement in orthopedic outcome score and reduction in IL-1 $\beta$, CXCL13, and TNF- $\alpha$ in synovial fluid of osteoarthritis patients following arthroscopic knee surgery
}

\author{
Z.M. $\mathrm{Li}^{1 *}$ and M. $\mathrm{Li}^{2 *}$ \\ ${ }^{1}$ Department of Orthopedics, Dezhou People's Hospital, \\ Dezhou, Shandong, China \\ ${ }^{2}$ Department of Pathology, Dezhou People's Hospital, \\ Dezhou, Shandong, China \\ *These authors contributed equally to this study. \\ Corresponding author: Z.M. Li \\ E-mail: ZhimingLizxc@163.com
}

Genet. Mol. Res. 16 (3): gmr16039487

Received October 27, 2016

Accepted April 12, 2017

Published July 6, 2017

DOI http://dx.doi.org/10.4238/gmr16039487

Copyright (C) 2017 The Authors. This is an open-access article distributed under the terms of the Creative Commons Attribution ShareAlike (CC BY-SA) 4.0 License.

\begin{abstract}
Knee osteoarthritis (KOA) is a common degenerative joint disease and immune system dysregulation has been implicated in its pathogenesis. The effect of arthroscopic knee surgery, an important method for KOA diagnosis and treatment, on the expression of immune regulators remains poorly understood. We aimed to investigate the clinical efficacy of such surgery and its impact on IL-1 $\beta$, CXCL13, and TNF- $\alpha$ expression in the knee joint synovial fluid of osteoarthritis patients. Fifty-seven patients having undergone arthroscopic knee surgery in our hospital were included. Visual analog scale (VAS) and Lysholm scores were recorded before surgery, and knee joint synovial fluid was collected during the procedure. According to Outerbridge cartilage damage score (grade $0,1,2,3$, or 4), patients were divided into five groups. In addition, VAS and Lysholm scores were recorded
\end{abstract}


and knee joint synovial fluid was collected after a six-month followup period. Expression of IL-1 $\beta$, CXCL13, and TNF- $\alpha$ in synovial fluid samples was then measured. In each group, levels of these molecules and VAS and Lysholm scores were significantly lower after surgery $(\mathrm{P}$ $<0.05)$. IL-1 $\beta$, CXCL13, and TNF- $\alpha$ levels were significantly elevated in patients with higher cartilage damage scores compared to those with lower scores. Arthroscopic knee surgery can reduce IL-1 $\beta$, CXCL13, and TNF- $\alpha$ levels in the knee joint synovial fluid of osteoarthritis patients. Moreover, reduced presence of these molecules correlates with clinical improvement of this condition. Therefore, reduction in IL$1 \beta$, CXCL13, and TNF- $\alpha$ expression might be used as a factor for longterm osteoarthritis prognosis.

Key words: Arthroscopic knee surgery; Knee joint synovial fluid; Osteoarthritis; IL-1 $\beta$; CXCL13; TNF- $\alpha$

\section{INTRODUCTION}

Knee osteoarthritis (KOA) is a common degenerative joint disease whose incidence is increasing. Epidemiological investigations have estimated its prevalence to be $66 \%$ (AlHadithy et al., 2011), and more men are diagnosed with this condition than women (Mine et al., 2012). The etiology and pathogenesis of KOA have become popular research topics in recent years; however, the events involved in its development remain unclear. The influence of immune system dysfunction in the occurrence and development of KOA is currently receiving increasing attention (McAlindon et al., 2012; Katz et al., 2013).

Interleukin- $1 \alpha$ (IL-1 $\alpha)$ and IL-1 $\beta$ play a role in KOA pathogenesis. Under normal conditions, chondrocytes produce only small amounts of IL-1 $\beta$, but higher levels may be generated following development of KOA. Previous studies have shown that increased IL-1 $\alpha$ and IL-1 $\beta$ levels are found in not only cartilage and chondrocytes, but also in cartilaginous matrix in patients with KOA. Moreover, Yang et al. (2015) established that the concentration of IL-1 $\beta$ in synovial fluid is significantly higher in KOA patients than healthy controls, suggesting that synovial fluid IL-1 $\beta$ levels can be used to evaluate the severity of KOA and might be used as a novel indicator for the diagnosis and treatment of this condition.

Exogenous infection of genetically susceptible individuals leads directly to an imbalance between B cell and T cell subsets (Katz and Losina, 2014). Follicular helper T (Tfh) cells are a recently discovered category of helper T lymphocyte that express and secrete CXCR5 and IL-21. When CXCR5 interacts with B cell attracting chemokine-1 (BCA-1, also known as CXCL13), Tfh cells migrate to the germinal centers of secondary lymphoid follicles and activate $\mathrm{B}$ cells to produce antibodies.

Tumor necrosis factor- $\alpha(\mathrm{TNF}-\alpha)$ is an important mediator of the immune response and acute inflammation. Inflammatory chemokines and activation factors play key roles in the development and progression of inflammation. Animal experiments utilizing immunostaining have demonstrated that in stromal cells, TNF- $\alpha$ and its receptor are strongly expressed and that the degree of staining is highly correlated with KOA severity (Liu et al., 2015).

Both surgical and non-surgical treatments exist for KOA. As involves less trauma, quicker recovery, fewer complications, and lower cost compared with conventional surgery,

Genetics and Molecular Research 16 (3): gmr16039487 
arthroscopic knee surgery has been widely used for KOA diagnosis and treatment (Bellary et al., 2012). Despite the role of immune dysregulation in KOA pathogenesis and the changes in biochemical markers in the synovial fluid of patients with this condition following arthroscopic surgery (Nakajima et al., 2013), the effect of such surgery on the expression of certain immune regulators remains poorly understood. The present study was carried out to investigate the clinical efficacy of arthroscopic knee surgery and its effect on the expression of IL-1 $\beta$, CXCL13, and TNF- $\alpha$ in the knee joint synovial fluid of patients with osteoarthritis.

\section{MATERIAL AND METHODS}

\section{Subjects}

A total of 57 KOA patients of Dezhou People's Hospital (Dezhou, China) were enrolled into this study between December, 2014 and November, 2015 according to the "KOA diagnostic criteria" issued by Chinese Medical Association in 2007 (Bone science branch of Chinese medical association, 2007). The patient group comprised 28 men and 29 women with an average age of $61.5 \pm 14.2$ years (range: $57-88$ years) and an average disease duration of $18 \pm 5.7$ months (range: 1.2-168 months). The procedures involved were approved by the Medical Ethics Committee of Dezhou People's Hospital, and informed consent was obtained from all participants before commencing this study.

\section{Reagents and instruments}

Enzyme-linked immunosorbent assay (ELISA) kits for IL-1 $\beta$, CXCL13, and TNF- $\alpha$ were purchased from R\&D Systems (Minneapolis, MN, USA). The microplate reader used (model 680) was supplied by Bio-Rad Laboratories (Hercules, CA, USA), and the DYONICS endoscope utilized was manufactured by Smith \& Nephew (London, UK).

\section{Methods}

\section{Visual analog scale (VAS) and Lysholm ratings before and after surgery}

The same orthopedic physician obtained VAS and Lysholm ratings before surgery and after the six-month follow-up period. The VAS assessment for pain is self-completed by the respondent, who is asked to place a line perpendicular to the VAS line at the point representing their pain intensity (Hawker et al., 2011). A higher score indicates greater intensity. The following cut-off points have been recommended based on a previous study (Jensen et al., 2003): no pain $(0 \mathrm{~cm})$, mild pain $(1-3 \mathrm{~cm})$, moderate pain $(4-7 \mathrm{~cm})$, and severe pain $(8-10$ $\mathrm{cm}$ ). The Lysholm Knee Scoring Scale was implemented as described previously (Irrgang et al., 1998). Briefly, the revised scale includes eight items and individual items are scored differently, using individual scoring scales. Scores are categorized as excellent (0), good (1-3), fair (4-7), or poor (8-10).

\section{Specimen collection}

The same orthopedic physician performed surgery on all 57 KOA patients and

Genetics and Molecular Research 16 (3): gmr16039487 
collected synovial fluid, $2 \mathrm{~mL}$ of which was obtained from each patient and centrifuged. The resulting supernatant was collected and stored in a $-80^{\circ} \mathrm{C}$ freezer until needed.

\section{Arthroscopic debridement}

All parts of the knee joint were examined, and free tissue, hyperplastic synovium, and debris were removed. Meniscus injuries were sutured and capsular contractures were released.

\section{Outerbridge cartilage injury classification}

Articular cartilage damage was scored as follows: normal, 0 points; mild blisters on the surface, 1 point; shallow surface fissures smaller than $1.25 \mathrm{~cm}$ in diameter, 2 points; deep surface fissures larger than $1.25 \mathrm{~cm}$ in diameter, 3 points; full-thickness damage, 4 points.

\section{Cytokine expression}

Levels of IL-1 $\beta$, CXCL13, and TNF- $\alpha$ were measured by ELISA, following the manufacturer protocol.

\section{Statistical analysis}

SPSS 17.0 software (SPSS Inc., http://www-01.ibm.com/support/docview. wss?uid $=$ swg21476197) was used for statistical analysis. Data are reported as mean \pm standard deviations. The chi-square test was used to analyze count data, and the $t$-test was used for comparisons between groups. P values $<0.05$ were considered to indicate statistical significance.

\section{RESULTS}

\section{Outerbridge cartilage damage scores}

Of the 57 KOA patients, 10 (5 men:5 women), 11 (5:6), 14 (7:7), 15 (7:8), and 7 (4:3) scored $0,1,2,3$, and 4 points, respectively. The average ages in these categories were 58.5 $\pm 1.5,57.7 \pm 2.1,63.5 \pm 1.7,65.1 \pm 1.0$, and $61.5 \pm 1.5$ years, respectively. No significant differences were detected in regard to gender or age $(\mathrm{P}>0.05$; Table 1$)$.

Table 1. Outerbridge cartilage damage scores.
\begin{tabular}{|c|c|c|c|c}
\hline Outerbridge score & Cases & Male & Female & Age, years (means \pm SD) \\
\hline 0 & 10 & 5 & 5 & $58.5 \pm 1.5$ \\
\hline 1 & 11 & 5 & 6 & $57.7 \pm 2.1$ \\
\hline 2 & 14 & 7 & 7 & $63.5 \pm 1.7$ \\
\hline 3 & 15 & 7 & 8 & $65.1 \pm 1.0$ \\
\hline 4 & 7 & 4 & 3 & $61.5 \pm 1.5$ \\
\hline
\end{tabular}

$\mathrm{SD}=$ standard deviation

\section{IL-1 $\beta$ levels before and after surgery in each group}

ELISA revealed that IL-1 $\beta$ levels before surgery among patients having scored 0,1 , 2,3 , and 4 points with the Outerbridge system were $10.6 \pm 1.0,12.5 \pm 1.4,15.9 \pm 2.2,19.7 \pm$ 
4.5 , and $21.2 \pm 5.0 \mathrm{pg} / \mathrm{mL}$, respectively; those after surgery were $10.1 \pm 1.3,10.5 \pm 1.5,11.7 \pm$ $1.2,11.9 \pm 3.5$, and $15.5 \pm 1.8 \mathrm{pg} / \mathrm{mL}$, respectively. Compared to IL-1 $\beta$ levels before surgery, those measured afterwards were significantly lower $(\mathrm{P}<0.05$; Table 2$)$.

Table 2. Levels of IL-1 $\beta$ (pg/mL; means \pm standard deviations) before and after surgery in each group.

\begin{tabular}{l|c|c|c}
\hline Outerbridge score & Cases & Before surgery & After surgery \\
\hline 0 & 10 & $10.6 \pm 1.0$ & $10.1 \pm 1.3^{*}$ \\
\hline 1 & 11 & $12.5 \pm 1.4$ & $10.5 \pm 1.5^{*}$ \\
\hline 2 & 14 & $15.9 \pm 2.2$ & $11.7 \pm 1.2^{*}$ \\
\hline 3 & 15 & $19.7 \pm 4.5$ & $11.9 \pm 3.5^{*}$ \\
\hline 4 & 7 & $21.2 \pm 5.0$ & $15.5 \pm 1.8^{*}$ \\
\hline$* \mathrm{P}<0.05$ compared with $\mathrm{rL}-1 \beta$ level before surgery.
\end{tabular}

$* \mathrm{P}<0.05$ compared with IL-1 $\beta$ level before surgery.

\section{CXCL13 levels before and after surgery in each group}

Our ELISA results showed that CXCL13 levels before surgery in the $0,1,2,3$, and 4-point Outerbridge patient groups were $501.1 \pm 12.3,600.5 \pm 10.5,710.7 \pm 11.7,911.9 \pm$ 30.5 , and $1500.35 \pm 105.8 \mathrm{pg} / \mathrm{mL}$, respectively; those after surgery were $411.5 \pm 11.0,513.7 \pm$ $13.3,516.5 \pm 14.5,521.1 \pm 15.7$, and $522.5 \pm 16.7 \mathrm{pg} / \mathrm{mL}$, respectively. In comparison to those prior to surgery, CXCL13 levels afterwards were significantly decreased $(\mathrm{P}<0.05$; Table 3$)$.

Table 3. Levels of CXCL13 (pg/mL; means \pm standard deviations) before and after surgery in each group.

\begin{tabular}{l|c|c|c}
\hline Outerbridge score & Cases & Before surgery & After surgery \\
\hline 0 & 10 & $501.1 \pm 12.3$ & $411.5 \pm 11.0^{*}$ \\
\hline 1 & 11 & $600.5 \pm 10.5$ & $513.7 \pm 13.3^{*}$ \\
\hline 2 & 14 & $710.7 \pm 11.7$ & $516.5 \pm 14.5^{*}$ \\
\hline 3 & 15 & $911.9 \pm 30.5$ & $521.1 \pm 15.7^{*}$ \\
\hline 4 & 7 & $1500.35 \pm 105.8$ & $522.5 \pm 16.7^{*}$ \\
\hline $\mathrm{P}<0.05$ compared with CXCL13 level before surgery.
\end{tabular}

\section{TNF- $\alpha$ levels before and after surgery in each group}

According to ELISA, TNF- $\alpha$ levels before surgery among patients with $0,1,2,3$, and 4 points based on Outerbridge classification were $11.5 \pm 1.9,13.7 \pm 3.1,16.5 \pm 4.3,21.1 \pm$ 5.8 , and $22.5 \pm 6.9 \mathrm{pg} / \mathrm{mL}$, respectively; those after surgery were $10.1 \pm 1.0,11.5 \pm 2.1,11.7 \pm$ $2.3,12.2 \pm 1.5$, and $12.5 \pm 1.7 \mathrm{pg} / \mathrm{mL}$, respectively. TNF- $\alpha$ concentrations after surgery were significantly lower than those observed beforehand (except 0 -point group) $(\mathrm{P}<0.05$; Table 4$)$.

Table 4. Levels of TNF- $\alpha$ (pg/mL; means \pm standard deviations) before and after surgery in each group.
\begin{tabular}{l|c|c|c}
\hline Outerbridge score & Cases & Before surgery & After surgery \\
\hline 0 & 10 & $11.5 \pm 1.9$ & $10.1 \pm 1.0$ \\
\hline 1 & 11 & $13.7 \pm 3.1$ & $11.5 \pm 2.1^{*}$ \\
\hline 2 & 14 & $16.5 \pm 4.3$ & $1.7 \pm 2.3^{*}$ \\
\hline 3 & 15 & $21.1 \pm 5.8$ & $12.2 \pm 1.5^{*}$ \\
\hline 4 & 7 & $22.5 \pm 6.9$ & $12.5 \pm 1.7^{*}$ \\
\hline * $<0.05$ compared with TNF- $\alpha$ level before surgery
\end{tabular}

$* \mathrm{P}<0.05$ compared with TNF- $\alpha$ level before surgery.

Genetics and Molecular Research 16 (3): gmr16039487 


\section{VAS and Lysholm scores before and after surgery in each group}

Following surgery, VAS $(\mathrm{P}<0.05$; Table 5) and Lysholm scores $(\mathrm{P}<0.05$; Table 6) were significantly decreased.

Table 5. Visual analog scale scores before and after surgery in each group.

\begin{tabular}{l|c|c|c|c|c|c|c|c|c}
\hline \multirow{2}{*}{ Group } & \multirow{2}{*}{$\mathrm{N}$} & \multicolumn{9}{c|}{ Before surgery } & \multicolumn{3}{c}{ After surgery } \\
\cline { 3 - 11 } & & No pain & Mild pain & Moderate pain & Severe pain & No pain & Mild pain & Moderate pain & Severe pain \\
\cline { 3 - 11 } & & 0 & $1-3$ & $4-7$ & $8-10$ & 0 & $1-3$ & $4-7$ & 0 \\
\hline 0 & 10 & 0 & 7 & 3 & 0 & 10 & 0 & 0 \\
\hline 1 & 11 & 0 & 4 & 7 & 0 & 7 & 4 & 0 & 0 \\
\hline 2 & 14 & 0 & 4 & 10 & 0 & 5 & 5 & 4 & 0 \\
\hline 3 & 15 & 0 & 3 & 7 & 5 & 7 & 5 & 0 & 0 \\
\hline 4 & 7 & 0 & 0 & 0 & 7 & 4 & 3 & 0 \\
\hline Total & 57 & 0 & 18 & 27 & 12 & 33 & 17 & 7 & 0 \\
\hline
\end{tabular}

Table 6. Lysholm scores before and after surgery in each group.

\begin{tabular}{|c|c|c|c|c|c|c|c|c|c|}
\hline \multirow[t]{3}{*}{ Group } & \multirow[t]{3}{*}{$\mathrm{N}$} & \multicolumn{4}{|c|}{ Before surgery } & \multicolumn{4}{|c|}{ After surgery } \\
\hline & & Excellent & Good & Fair & Poor & Excellent & Good & Fair & Poor \\
\hline & & 0 & $1-3$ & $4-7$ & $8-10$ & 0 & $1-3$ & $4-7$ & $8-10$ \\
\hline 0 & 10 & 0 & 3 & 7 & 0 & 9 & 1 & 0 & 0 \\
\hline 1 & 11 & 0 & 3 & 7 & 1 & 8 & 3 & 0 & 0 \\
\hline 2 & 14 & 0 & 4 & 5 & 5 & 10 & 3 & 1 & 0 \\
\hline 3 & 15 & 0 & 0 & 7 & 8 & 11 & 3 & 1 & 0 \\
\hline 4 & 7 & 0 & 0 & 3 & 4 & 4 & 3 & 0 & 0 \\
\hline Total & 57 & 0 & 10 & 29 & 18 & 42 & 13 & 2 & 0 \\
\hline
\end{tabular}

\section{DISCUSSION}

$\mathrm{KOA}$, one of the most common joint diseases, is characterized by degenerative changes in articular cartilage and joint edge and subchondral bone hyperplasia. According to a World Health Organization survey, the incidence of osteoarthritis in people over 50 years of age is $60-70 \%$, and there are more than 190 million osteoarthritis patients worldwide (Apostolopoulos et al., 2012). In the Chinese population, 60\% of individuals over 60 years old have KOA. Therefore, the investigation of effective treatments for this condition employing minimally invasive surgery is of great importance.

Cytokines in synovial fluid play important roles as mediators of inflammation, transmitting inflammatory signals to cells. Cytokines produced as a result of synovitis can spread through synovial fluid, activating chondrocytes to secrete further inflammatory cytokines. Such molecules, specifically, TNF- $\alpha$, CXCL13, and IL- $1 \beta$, are substantially involved in the occurrence and development of KOA. Lipopolysaccharides cause synovial tissue to secrete IL-1. Following IL-1 stimulation, articular chondrocytes synthesize large quantities of collagen types I and III, and reduce production of types II and IX. In addition, IL-1 can regulate expression of cartilage proteolytic enzymes such as metalloproteases, and may cause osteoarthritis by stimulating osteoblasts, altering the normal load-bearing structure of bone. One cause of the pain associated with KOA is the presence of a large number of inflammatory cytokines, including IL-1 $\beta$ and TNF- $\alpha$, in the synovial fluid (He et al., 2011; Nakayama et al., 2011).

Higher IL- $1 \beta$ and TNF- $\alpha$ levels are associated with increased KOA severity (Nelson, 2014; Sharma, 2016). In the present study, IL-1 $\beta$, CXCL13, and TNF- $\alpha$ expression positively correlated with Outerbridge score, suggesting that the extent of cartilage damage in patients

Genetics and Molecular Research 16 (3): gmr16039487 
with KOA can be estimated by measuring levels of inflammatory cytokines, particularly of those tested here, in synovial fluid.

Arthroscopic knee surgery has become a key technique for KOA diagnosis and treatment since its first use in the 1960s, owing to its benefits of less trauma, quicker recovery, fewer complications, and lower cost compared wti conventional surgery (Dulay et al., 2015; Yu and Hunter, 2015; Zengini et al., 2016). In arthroscopy, the joint cavity can be washed out, removing pain-causing inflammatory mediators, relieving swelling, and extracting cartilage and synovial tissue debris. It can also be used to repair ligament and meniscus injuries, improve the structure and function of joints, prevent deterioration or development of degenerative disease of the knee, and relieve pain.

Jackson and Dieterichs (2003) found that removal of free tissue and injured areas of meniscus using arthroscopy significantly improved the clinical symptoms of 200 patients with knee pain. Similarly, Sprague (1981) performed synovectomy, osteophyte removal, and repair of damaged meniscus using arthroscopic debridement for 69 KOA patients, $74 \%$ of whom subsequently showed significant improvement. Dervin et al. (2003) carried out arthroscopic surgery on 126 patients who were then followed up for 24 months, with outcomes being measured using the Short Form-36 Health Survey and Western Ontario and McMaster Universities Osteoarthritis Index. Postoperative joint function was found to be excellent for 56 patients $(44 \%)$, fair for $38(30 \%)$, and poor for $32(25 \%)$. Twenty-seven patients with poor postoperative joint function $(21 \%)$ underwent knee replacement surgery, three $(2.3 \%)$ had elective tibial osteotomy, and two (1.6\%) received a second arthroscopic knee operation. Ambrozaitis et al. (2006) showed the clinical effectiveness of arthroscopic knee surgery to be between 50 and 70\%. Finally, Krystallis et al. (2004) analyzed the clinical indications for arthroscopy, concluding that such surgery achieves beneficial clinical effects when joint cavities are stenotic and preoperative joint function is good.

In each patient group of the present study, IL-1 $\beta$, CXCL13, and TNF- $\alpha$ levels, as well as VAS and Lysholm scores, were significantly reduced after surgery $(\mathrm{P}<0.05)$. This suggests that arthroscopic debridement can achieve the desired clinical effect. Although arthroscopic knee surgery cannot ultimately alter the pathology of KOA, it can rapidly improve joint function, reduce joint pain, and postpone arthroplasty or arthrodesis. However, the exact mechanism by which such surgery decreases levels of IL-1 $\beta$, CXCL13, and TNF- $\alpha$ remains unclear and requires further investigation.

\section{CONCLUSIONS}

In conclusion, arthroscopic knee surgery can reduce the concentration of IL-1 $\beta$, CXCL13, and TNF- $\alpha$ in knee joint synovial fluid. Decreased levels of these molecules in knee joint synovial fluid correlate with improvements in the clinical symptoms of patients with KOA.

\section{Conflicts of interest}

The authors declare no conflict of interest.

\section{ACKNOWLEDGMENTS}

We thank the anonymous reviewers for reviewing this manuscript.

Genetics and Molecular Research 16 (3): gmr16039487 


\section{REFERENCES}

Al-Hadithy N, Gikas P, Mahapatra AM and Dowd G (2011). Review article: Plica syndrome of the knee. J. Orthop. Surg. (Hong Kong) 19: 354-358. https://doi.org/10.1177/230949901101900319

Ambrozaitis KV, Kontautas E, Spakauskas B and Vaitkaitis D (2006). Pathophysiology of acute spinal cord injury. Medicina (Kaunas) 42: 255-261.

Apostolopoulos AP, McConnell B, Manta A and Zafiropoulos G (2012). The incidence of infrapatellar plicae in the elderly Welsh population. Folia Morphol. (Warsz) 71: 194-197.

Bellary SS, Lynch G, Housman B, Esmaeili E, et al. (2012). Medial plica syndrome: a review of the literature. Clin. Anat. 25: 423-428. https://doi.org/10.1002/ca.21278

Bone Science Branch of Chinese Medical Association (2007). Osteoarthritis diagonosis guidelines. The Chinese Orthopedic Journal 27: 793-796.

Dervin GF, Stiell IG, Rody K and Grabowski J (2003). Effect of arthroscopic débridement for osteoarthritis of the knee on health-related quality of life. J. Bone Joint Surg. Am. 85-A: 10-19. https://doi.org/10.2106/00004623-200301000-00003

Dulay GS, Cooper C and Dennison EM (2015). Knee pain, knee injury, knee osteoarthritis \& work. Best Pract. Res. Clin. Rheumatol. 29: 454-461. https://doi.org/10.1016/j.berh.2015.05.005

Hawker GA, Mian S, Kendzerska T and French M (2011). Measures of adult pain: Visual Analog Scale for Pain (VAS Pain), Numeric Rating Scale for Pain (NRS Pain), McGill Pain Questionnaire (MPQ), Short-Form McGill Pain Questionnaire (SF-MPQ), Chronic Pain Grade Scale (CPGS), Short Form-36 Bodily Pain Scale (SF-36 BPS), and Measure of Intermittent and Constant Osteoarthritis Pain (ICOAP). Arthritis Care Res. (Hoboken) 63 (Suppl 11): S240-S252. https://doi.org/10.1002/acr.20543

He R, Yang L and Guo L (2011). Painful locking of the knee due to bucket handle tear of mediopatellar plica. Chin. J. Traumatol. 14: 117-119.

Irrgang JJ, Snyder-Mackler L, Wainner RS, Fu FH, et al. (1998). Development of a patient-reported measure of function of the knee. J. Bone Joint Surg. Am. 80: 1132-1145. https://doi.org/10.2106/00004623-199808000-00006

Jackson RW and Dieterichs C (2003). The results of arthroscopic lavage and debridement of osteoarthritic knees based on the severity of degeneration: a 4- to 6-year symptomatic follow-up. Arthroscopy 19: 13-20. https://doi.org/10.1053/jars.2003.50022

Jensen MP, Chen C and Brugger AM (2003). Interpretation of visual analog scale ratings and change scores: a reanalysis of two clinical trials of postoperative pain. J. Pain 4: 407-414. https://doi.org/10.1016/S1526-5900(03)00716-8

Katz JN and Losina E (2014). Arthroscopic partial meniscectomy for degenerative tears: where do we stand? Osteoarthritis Cartilage 22: 1749-1751. https://doi.org/10.1016/j.joca.2014.07.016

Katz JN, Brophy RH, Chaisson CE, de Chaves L, et al. (2013). Surgery versus physical therapy for a meniscal tear and osteoarthritis. N. Engl. J. Med. 368: 1675-1684. https://doi.org/10.1056/NEJMoa1301408

Krystallis CT, Kirkos JM, Papavasiliou KA, Konstantinides PA, et al. (2004). Arthroscopic debridement of the osteoarthritic knee under local anaesthesia. Acta Orthop. Belg. 70: 260-267.

Liu KG, He QH, Tan JW and Liao GJ (2015). Expression of TNF- $\alpha$, VEGF, and MMP-3 mRNAs in synovial tissues and their roles in fibroblast-mediated osteogenesis in ankylosing spondylitis. Genet. Mol. Res. 14: 6852-6858. https://doi. org/10.4238/2015.June.18.28

McAlindon TE, Driban JB and Lo GH (2012). Osteoarthritis year 2011 in review: clinical. Osteoarthritis Cartilage 20: 197-200. https://doi.org/10.1016/j.joca.2011.12.015

Mine T, Ihara K, Kawamura H, Seto T, et al. (2012). Shelf syndrome of the knee in elderly people: a report of three cases. J. Orthop. Surg. (Hong Kong) 20: 269-271. https://doi.org/10.1177/230949901202000229

Nakajima A, Nakagawa K, Aoki Y, Sonobe M, et al. (2013). Changes in synovial fluid biochemical markers following arthroscopic surgery in patients with knee osteoarthritis. Rheumatol. Int. 33: 209-214. https://doi.org/10.1007/ $\underline{\mathrm{s} 00296-012-2374-8}$

Nakayama A, Sugita T, Aizawa T, Takahashi A, et al. (2011). Incidence of medial plica in 3,889 knee joints in the Japanese population. Arthroscopy 27: 1523-1527. https://doi.org/10.1016/j.arthro.2011.06.022

Nelson FR (2014). A background for the management of osteoarthritic knee pain. Pain Manag 4: 427-436. https://doi. org/10.2217/pmt. 14.40

Sharma L (2016). Osteoarthritis year in review 2015: clinical. Osteoarthritis Cartilage 24: 36-48. https://doi.org/10.1016/j. joca.2015.07.026

Sprague NF, 3rd (1981). Arthroscopic debridement for degenerative knee joint disease. Clin. Orthop. Relat. Res. 160: 118-123.

Yang L, Zhang J and Wang G (2015). The effect of sodium hyaluronate treating knee osteoarthritis on synovial fluid interleukin $-1 \beta$ and clinical treatment mechanism. Pak. J. Pharm. Sci. 28 (Suppl): 407-410.

Genetics and Molecular Research 16 (3): gmr16039487 
Yu SP and Hunter DJ (2015). Managing osteoarthritis. Aust. Prescr. 38: 115-119. https://doi.org/10.18773/ austprescr.2015.039

Zengini E, Finan C and Wilkinson JM (2016). The genetic epidemiological landscape of hip and knee osteoarthritis: where are we now and where are we going? J. Rheumatol. 43: 260-266. https://doi.org/10.3899/jrheum.150710

Genetics and Molecular Research 16 (3): gmr16039487 